\title{
К ВОПРОСУ О СТАНДАРТИЗАЦИИ НОРМ ПОЛОС ОТВОДА АВТОМОБИЛЬНЫХ ДОРОГ
}

\section{Владимир Александрович Костеша}

Государственный университет по землеустройству, 105064, г. Москва, ул. Казакова, 15, старший преподаватель кафедры геодезии и геоинформатики, тел. (926)574-11-99, e-mail: vlkostesha@mail.ru

\section{Ольга Алексеевна Марычева}

Государственный университет по землеустройству, 105064, Москва, ул. Казакова, 15, обучающийся, тел. (915) 038-04-95, e-mail: 01echka@bk.ru

Данная статья посвящена проблемам определения границ полос отвода автомобильных дорог. Отдельное внимание уделяется вопросам нормативно-правового обеспечения установления полос отвода и несоответствию реальных размеров и конфигурации полос отвода нормативным значениям. Предложены пути совершенствования существующего состояния с использованием современных геоинформационных систем. Разработана схема работ по приведению полос отвода к нормативным показателям.

Ключевые слова: автомобильная дорога, земельный участок, полоса отвода, мониторинг, геоинформационное обеспечение, геопортал

\section{TO THE QUESTION OF NORM STANDARDIZATION OF HIGHWAY ROAD LAND}

\section{Vladimir A. Kostesha}

State University of Land Management, 15, Kazakova St., Moscow, 105064, Russia, Senior Lecturer, Department of Geodesy and Geoinformatics, phone: (926)574-11-99, e-mail: vlkostesha@mail.ru

\section{Olga A. Marycheva}

State University of Land Management, 15, Kazakova St., Moscow, 105064, Russia, Student, phone: (915)038-04-95, e-mail: 01echka@bk.ru

This article is devoted to modern problems that exist now in the field of the establishment and operation of road lands for highways. Special attention is paid to the issues of regulatory support for the establishment of road lands. The ways of solving the existing problems with the use of modern geoinformation systems, such as the geoportal GIS FAD "Central Russia".

Keywords: highways, land plot, right-of-way, road land, monitoring, geoinformation support, geoportal

Полоса отвода по своей сути является земельным участком, предназначенным для размещения конструктивных элементов автодороги и дорожных сооружений.

Согласно Градостроительному кодексу и Федеральному закону от 08.11.2007 N 257-Ф3 «Об автомобильных дорогах и о дорожной деятельности в Российской Федерации и о внесении изменений в отдельные законодательные акты Российской Федерации» $[1,2]$, основанием для определения границ полосы отвода является документация по планировке территории [3]. При подготовке 
документации по планировке территории, разрабатываемой для размещения автодорог и (или) объектов сервиса, учитываются нормы отвода земель, которые утверждаются Правительством РФ.

Нормативные показатели ширины полосы отвода закреплены в Постановлении Правительства Российской Федерации N 717 «О нормах отвода земель для размещения автомобильных дорог и (или) объектов дорожного сервиса» от 2 сентября 2009 г. [4].

Правительство Российской Федерации, Федеральные органы исполнительной власти, высшие органы исполнительной власти, высшие органы государственной власти субъектов РФ и органы местного самоуправления определяют порядок установления и использования полос отвода автодорог соответственно федерального, регионального, межмуниципального и местного значения.

В рамках реализации транспортной стратегии [5] и федеральных проектов «Безопасность дорожного движения», «Общесистемные меры по развитию дорожного хозяйства», «Дорожная сеть» предусмотрены работы по увеличению количества автодорог, соответствующих нормативным требованиям, уменьшению перегруженных участков, внедрению современных технических стандартов и требований.

Ширина полос отвода и размеры земельных участков, которые выделены для размещения автодорог, определяются с учетом категории дороги [6], количества полос движения, высоты насыпи или глубины выемки и др.

Нормативные показатели ширины представлены в виде таблиц в приложении к Постановлению Правительства РФ N 717. Показатели для автомобильных дорог, располагаемых в насыпях, определены в таблицах 1-7, в выемках - в таблицах 8-14, в раскрытых выемках - таблица 15.

Границы полос отвода автомобильных дорог, которые требуют индивидуального решения земляного полотна (имеющие превышение одного из откосов насыпи или глубины выемки более $12 \mathrm{M}$, располагающиеся на подходах к мостам, путепроводам или тоннелям) не нормированы законом и определяются расчетным методом в ходе подготовки документов территориального планирования, проектной документации и инженерных изысканий.

Кроме того, в данном законодательном акте представлена таблица усредненных показателей площади полосы отвода на 1 линейный километр автомобильной дороги в зависимости от категории дороги, количества полос движения и уклона местности.

Стоит отметить, что при разработке документации по планировке территории одним из наиболее трудоемких является определение границ полос отвода. Причем, положения таблиц 1-15 используются крайне редко, в силу того, что большинство полос отвода устанавливается в соответствии с индивидуальными проектными решениями. Некоторые вопросы, связанные с правовым режимом, автоматизацией и особенностями установления полосы отвода автомобильных дорог рассмотрены в научной литературе [7-11]. 
Наличие такого рода системы усложняет конфигурацию и процесс определения границ полос отвода автодорог. Существующая на данный момент тенденция захвата полос отвода частными землевладельцами при постановке земельных участков на государственный кадастровый учет усугубляет ситуацию и приводит к уменьшению площадей земель, находящихся в федеральной собственности, собственности субъектов РФ и собственности муниципалитетов. Незаконное использование полосы отвода оказывает негативное влияние, в первую очередь на безопасность дорожного движения, помимо этого, процессы капитального ремонта, реконструкции и модернизации автомобильных дорог становятся более трудоемкими и финансово затратными.
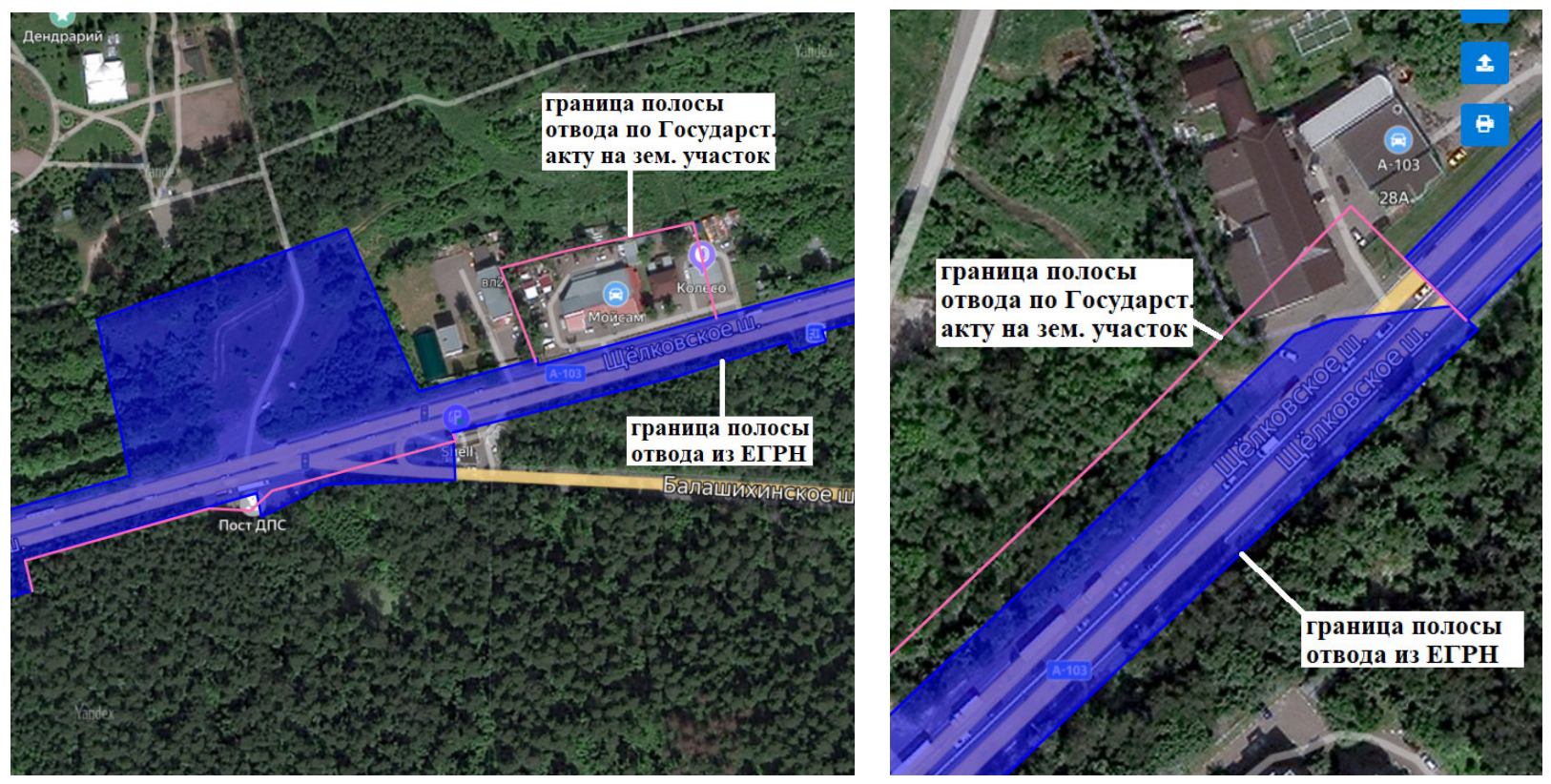

Рис. 1. Нарушение границ полосы отвода автомобильной дороги А-103

На рис. 1 видно, что из-за захвата земли для строительства магазина, произошло уменьшение площади полосы отвода автомобильной дороги, вследствие чего недостающая площадь была добавлена из земель, собственность на которые не разграничена, что приводит к усложнению (ухудшению) конфигурации полосы отвода.

Сравним площадь полосы отвода, указанную в государственном акте на право бессрочного пользования землей № 000247 (рис. 2), выданного ФКУ «Центравтомагистраль» под строительство автодороги. В данном документе указана общая площадь земель - 29,09 га. Для сравнения возьмем площадь, указанную на публичной кадастровой карте, согласно которой, земельный участок данной полосы отвода имеет кадастровый номер 50:15:0602103:5 (рис. 3) и площадь 30,00 га. Следовательно, делаем вывод о том, что реальная площадь полосы отвода отличается от исходной на 0,91 га. 


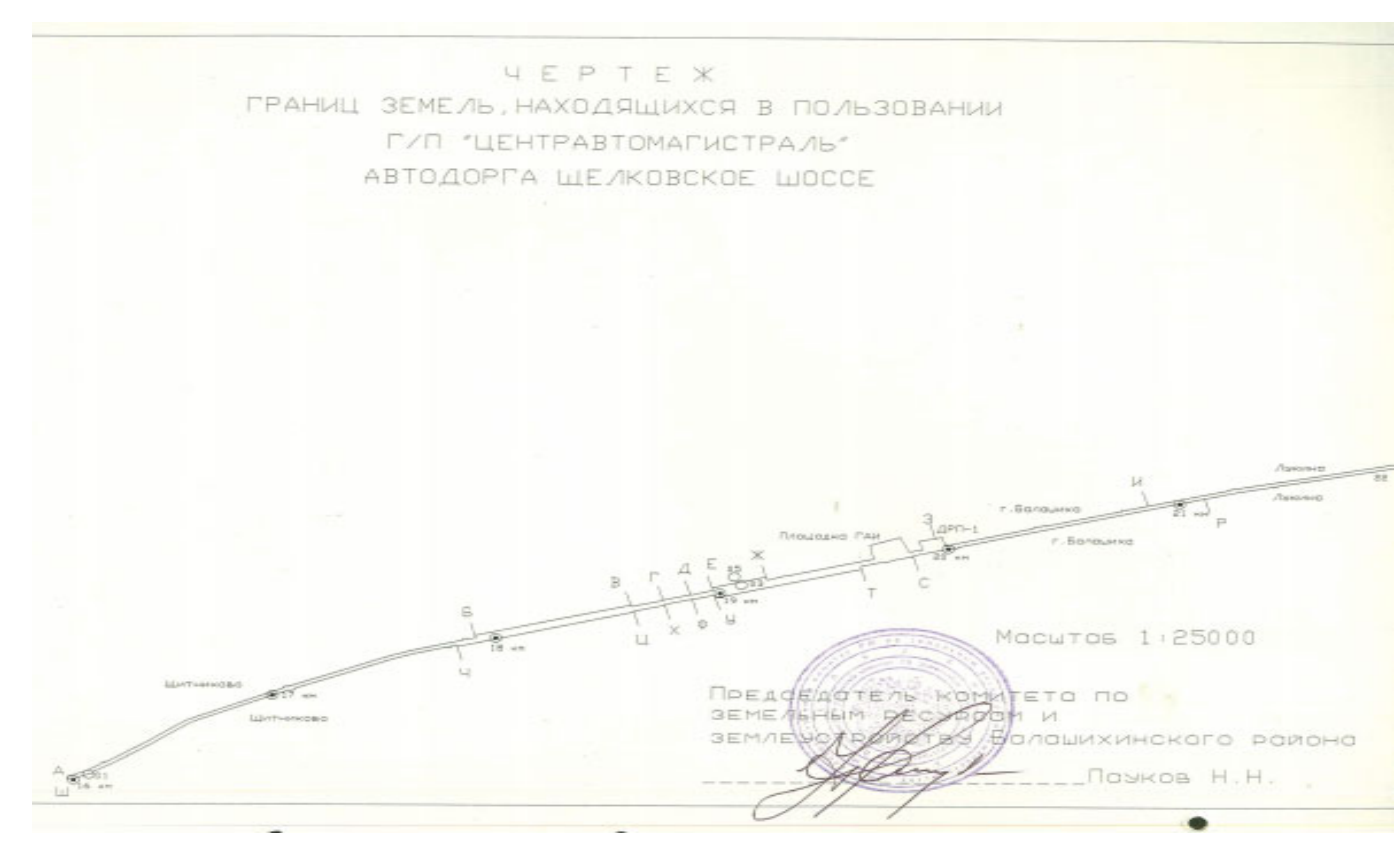

Рис. 2. Чертеж границ полосы отвода (Приложение к Гос. Акту)

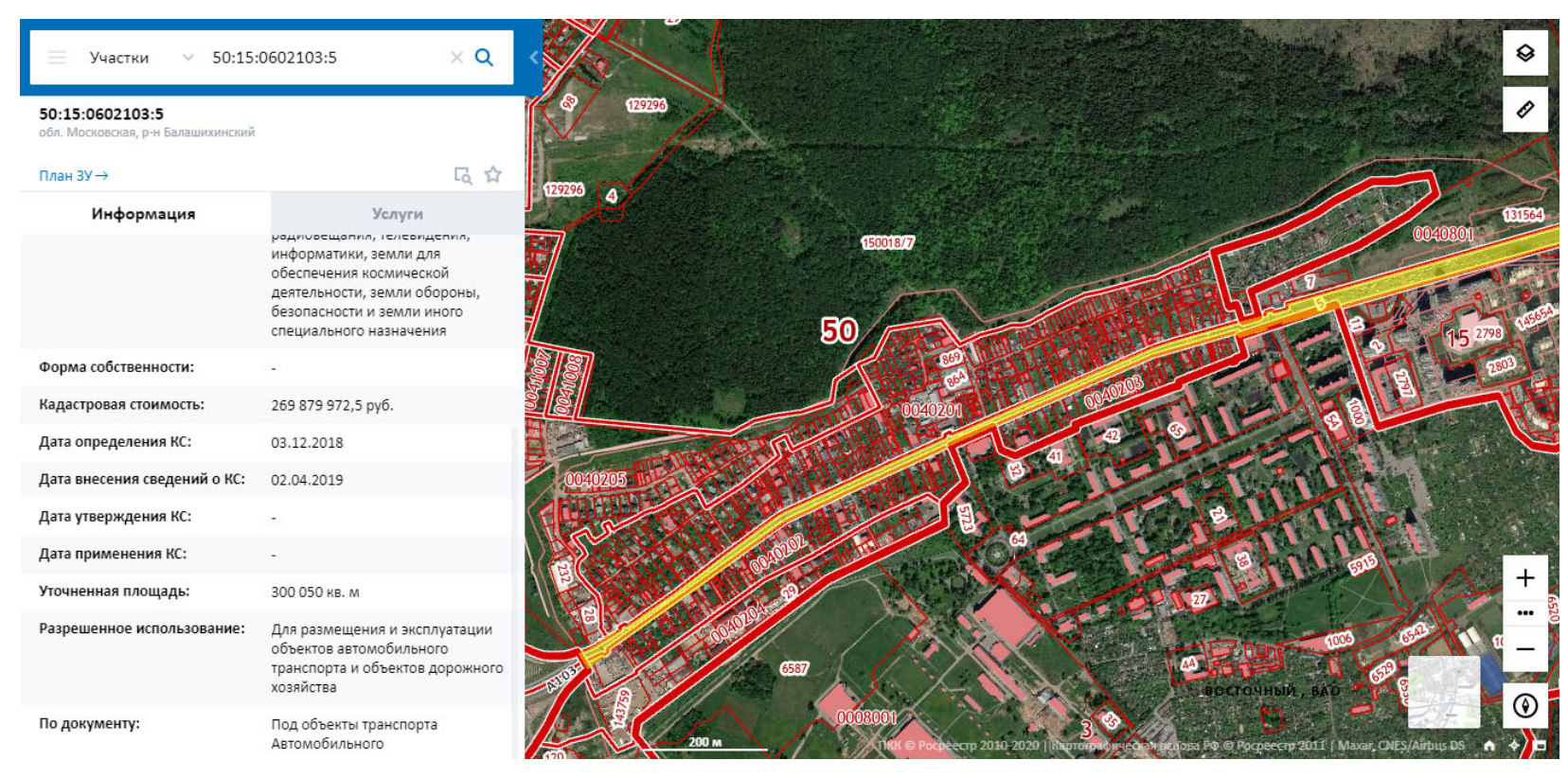

Рис. 3. Земельный участок 50:15:0602103:5

При детальном рассмотрении земельного участка полосы отвода можно отметить, что изменение площади произошло из-за расширений полосы отвода и не требует устранения. Однако конфигурация очень сильно изменена. Выявлены различные факты захвата полосы отвода частными землевладельцами (рис. 1). В случаях выявления фактов незаконного захвата земель в границах полос отвода для производства работ по реконструкции или расширению дорог владелец должен выкупить часть земли, которая согласно первоначальному государственному акту принадлежала ему. 
Ситуация осложняется наличием нарушений, связанных с несанкционированным использованием земель в границах полос отвода.

На основании всего вышесказанного можно сделать вывод о том, что в настоящее время требуется произвести модернизации сферы проектирования и определения границ полос отвода автомобильных дорог. Совершенствование процесса установления полос отвода позволило бы ввести упрощенный порядок, по которому ширина полосы отвода будет устанавливаться в зависимости от категории автомобильной дороги и количества полос движения.

После изменения регламентов считаем необходимым привести границы полос отвода к нормативным показателям, что упростит и ускорит процессы, связанные с реконструкцией автомобильных дорог. В общем виде процесс приведения полос отвода к нормативным величинам можно представить в виде блоксхемы, представленной на рис. 4.

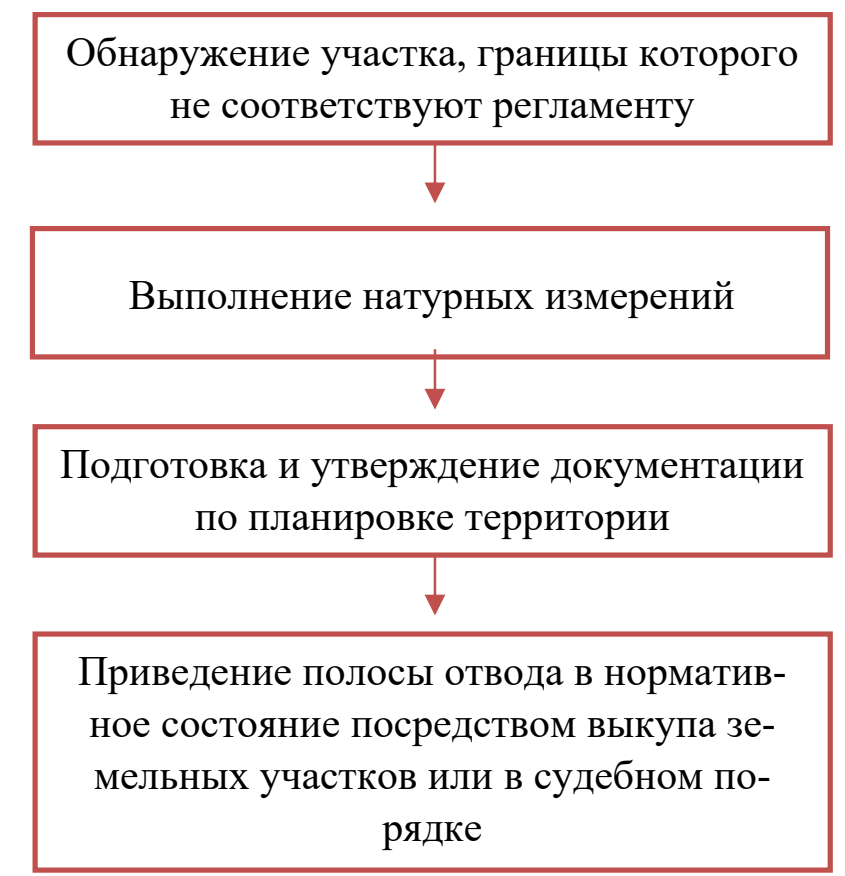

Рис. 4. Порядок работ по приведению полосы отвода к нормативным величинам

Для оперативного обнаружения земельных участков, границы которых не соответствуют регламенту, предлагается использовать публичную кадастровую карту и геопорталы автомобильных дорог, такие как ГИС ФАД «Центральная Россия»[12].

Геопортал (рис. 5) является геоинформационной системой, разработанной на базе API Яндекс.Карт, и содержит информацию об объектах капитального строительства, земельных участках, придорожных полосах, километровых столбах, объектах дорожного сервиса и др. федеральных автомобильных дорог, расположенных на территории Московской, Калужской и Владимирской областей. Использование архитектуры геопортала для создания подобных 
геоинформационных систем для дорог в других регионах Российской Федерации позволило бы сделать систему определения и эксплуатации полос отвода автодорог прозрачной, упростить и усовершенствовать процесс приведения реальных границ полос отвода к их нормативной конфигурации.

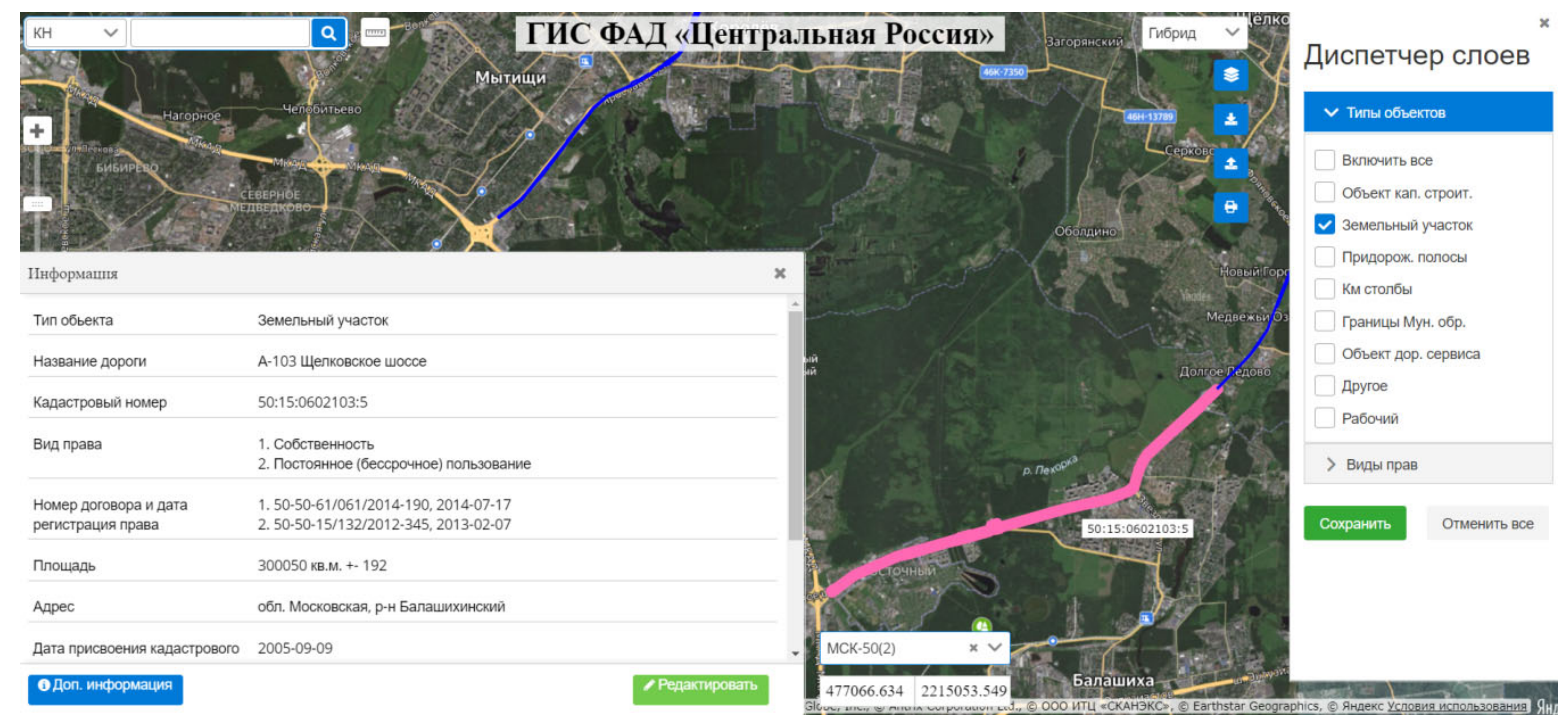

Рис. 5. Геопортал ГИС ФАД «Центральная Россия»

Таким образом, в силу сложности системы определения границ полос отвода и процессов, связанных с захватом земель в их границах, существует потребность совершенствования системы установления и эксплуатации полос отвода. Необходима разработка упрощенных регламентов и инвентаризации с целью приведения полос отвода к нормативным показателям. Геопортал в данном случае выступает средством геоинформационного обеспечения, включающим сведения об объектах автодорожного комплекса и их параметрах и упрощает работы по мониторингу и инвентаризации полос отвода. Также, геопортал, благодаря существующей возможности загрузки в него нескольких границ полос отвода, может автоматизировать и значительно ускорить инвентаризацию, а, следовательно, и весь процесс приведения полос отвода к нормативным величинам.

\section{БИБЛИОГРАФИЧЕСКИЙ СПИСОК}

1. Градостроительный кодекс Российской Федерации" от 29.12.2004 N 190-Ф3 (ред. от 31.07.2020) // Собрание законодательства Российской Федерации, 2005, №1, ст. 17; №30, ст. 3122 .

2. Федеральный закон «Об автомобильных дорогах и о дорожной деятельности в Российской Федерации и о внесении изменений в отдельные законодательные акты Российской Федерации» 08.11.2007 N 257-Ф3 (ред. от 20.07.2020)// Собрание законодательства РФ. - 2007. № 46. - Ст. 5553.

3. Постановление Правительства РФ от 12 мая 2017 г. № 564 «Об утверждении Положения о составе и содержании проектов планировки территории, предусматривающих размещение одного или нескольких линейных объектов»: Консорциум Кодекс. - URL: http://docs.cntd.ru/document/436733514 (Дата обращения 12.11.2020). - Текст электронный. 
4. Постановление Правительства РФ от 02.09.2009 N 717 (ред. от 11.03.2011) «О нормах отвода земель для размещения автомобильных дорог и (или) объектов дорожного сервиса».

5. Транспортная стратегия РФ на период до 2030 года, утверждена распоряжением Правительства РФ №1734-р от 22.11.2008г.

6. Постановление Правительства РФ от 28 сентября 2009 года № 767 «О классификации автомобильных дорог в Российской Федерации»: Консорциум Кодекс. - URL: http://docs.cntd.ru/document/902177298 (Дата обращения 12.11.2020). - Текст электронный.

7. Гатина Н.В. Особенности размещения линейных объектов на территории г. Томска / Н. В. Гатина, К.В. Студенова // Материалы Международного научного симпозиума имени академика М.А. Усова «Проблемы геологии и освоения недр». - 2016. - 597- 598 С.

8. Шабаев С.Н., Григорьева Т.И., Губина А.А. Совершенствование методов проведения землеустройства линейных объектов с помощью автоматизации процесса расчета границы полосы отвода // Вестник Кузбасского государственного технического университета. - 2017.

9. Рышкова Е.В., Рышкова Л.В. Правовой режим земель автомобильного транспорта: перспективы развития // Ученые записки Крымского федерального университета имени В. И. Вернадского Юридические науки. - 2016. - Т. 2 (68). № 4. - С. 106-114.

10. Алтынцев М.А. Автоматизированное определение характерных линий автомобильных дорог по данным мобильного лазерного сканирования // Интерэкспо Гео-Сибирь. - 2016.

11. Ковязин В.Ф., Пинчук А.А. Отвод земельного участка для строительства автомобильной дороги в Гатчинском районе Ленинградской области // Астраханский вестник экологического образования № 4 (34). - 2015. С. 71-76.

12. Костеша В.А., Платонов И.А., Чистякова Е.А. Использование ВЕБ-ГИС для управления автомобильными дорогами // Труды научного конгресса 21-го Международного научнопромышленного форума: в 3-х томах. - 2019. С. 300-303.

(C) B. A. Костеша, О. А. Марычева, 2021 